\title{
Motor Development in Children Living within Resource Poor Areas of the Western Cape
}

\begin{abstract}
Introduction: In 1986, Irwin-Carruthers tested 681 Black African babies from the Western Cape and concluded that the South African sample was in advance of the Denver sample both in fine and gross motor behaviour. This study was to determine whether the motor development of isiXhosa speaking children from the same area was still advanced compared to their North American counterparts.

Method: The Bayley Scales of Infant Development-II were administered to 86 children attending well baby clinics, between the ages of 1-36 months.

Results: The mean motor developmental quotient was $92(S D=15)$. Twenty eight percent of the sample was either significantly or mildly delayed. No socio-economic or maternal characteristics were associated with this score. Conclusion: The reasons for the decrease in performance are not clear. The socio-economic situation of the mothers was poor and there were a large number of single mothers whose sole source of income was government child support grants. It is likely that the cause of the decrease is multi-factorial. The mothers are clearly in need of emotional and financial support. It is suggested that the introduction of stimulation programmes might be useful in reducing the long term impact of this delayed development.
\end{abstract}

\section{KEY WORDS: INFANT DEVELOPMENT, POVERTY, BAYLEY SCALES OF INFANT DEVELOPMENT, HIV.}

\section{INTRODUCTION}

The documentation of the status of a child's development, compared with their peers, is a useful method of monitoring the child's emotional and physical health. The development of motor skills is necessary for the child's participation in normal life, including learning tasks, self-care tasks and play skills (Goyen and Lui, 2002). Although developmental delay does not necessarily result in a developmental coordination disorder, there is evidence that children who show early signs of motor delay might be at risk for developing this condition (Barnhart et al., 2003) or attention deficit disorder (Denckla, 2005). Barnhart et al, (2003) state that children do not outgrow "clumsiness" and outline the poor psychosocial skills which may be associated with motor dysfunction, ranging from inappropriate class room behaviour to decreased self-esteem in adolescents.

In order to determine whether the individual child is achieving his developmental objectives at an appropriate age, it becomes necessary to compare his performance with others, usually through the use of a normed scale of infant development. For children in developing countries, it may be difficult to identify a norm referenced develop- mental scale which will be useful in the target population. It is clear that "normal development" of children is influenced by many factors, including cultural norms and socio-economic status, apart from individual variation. It has been documented that children growing up in poverty are more likely to have developmental problems and that these problems may be more severe (Abbott and Bartlett, 1999). Maternal depression has a major influence on the interaction between mother and child, a situation that has been documented in an indigent peri-urban South African context and as such maternal mood might also influence the child's motor and mental development (Cooper et al., 2002).

In South Africa, the HIV/AIDS pandemic is an important factor to consider when discussing the development of children. HIV has been found consistently to affect motor and cognitive development (Potterton and Eales, 2001) and any study of typically developing children should attempt to exclude children who are infected. In one of the areas under study, $13 \%$ of women attending antenatal clinics tested HIV positive, (Coetzee et al., 2004) and the number of children in South Africa who were infected was estimated to be more than 250000 in 2001 (UNAIDS, 2002). The prevalence of HIV is high, and it is likely that any sample of children from the townships under study areas will include children with HIV.

Taking cognisance of the need to investigate the validity of a North American developmental scale, the Denver Development Screening Test, Irwin-Carruthers tested 681 Black African babies from the Western Cape and concluded that the South African sample was in advance of the Denver sample both in fine and gross motor behaviour (Irwin-Carruthers, 1986). Some activities, such as bearing some weight through the legs, sitting without support and getting into sitting were

\section{CORRESPONDENCE TO:}

J Jelsma

Division of Physiotherapy,

School of Health and

Rehabilitation Sciences,

Faculty of Health Sciences,

University of Cape Town,

Anzio Road,

Observatory 7925 ,

Fax: (27-21) 448-8157

Tel: (27-21) 406-6402

E-mail: Jennifer.Jelsma@uct.ac.za 
achieved by $90 \%$ of the children in excess of two months earlier than the age at which $90 \%$ of the Denver sample achieved these behaviours. She postulated that the universal practice of mothers carrying infants on their backs stimulated dynamic postural responses which enhanced the early acquisition of motor skills.

In a similar attempt to ensure that the norms of scales developed elsewhere are valid for South African children, the authors have been involved in other pilot studies which have tested the Bayley Scales of Infant Development, Second Version (BSID-II) (Bayley, 1993) and the Alberta Infant Motor Scale (AIMS) (Piper et al., 1994) on typically developing children from isiXhosa speaking families in resource poor areas of Cape Town. The results of these studies indicated that children with no evidence of immuno-suppression were performing below the norms predicted by both tests. In the one study using a sample of 25 typically developing children as a control group for children with HIV, the motor developmental quotient (DQ) was found to be 93.3 ( $\mathrm{SD}=18.2$ ) on the BSID (Matyida and Jelsma, 2004). In another similar study, the DQ of 74 typically developing children was found to be 91.71 $(\mathrm{SD}=16.78)$ using the Alberta Infant Motor Scale (Jelsma et al., 2004b). In both cases, as the motor quotient is defined as the developmental age divided by the chronological age multiplied by 100 , the mean DQ should be 100, with a standard deviation of 15 .

The BSID-II (Bayley, 1993) were developed and normed in the US on a large, stratified sample of children. The scales have been used extensively in South Africa and are regarded as being a valid and reliable test of motor performance (Potterton and Eales, 2001). Although the Denver Scales (Frankenburg and Dodds, 1967) were used in the study by Irwin-Carruthers (Irwin-Carruthers, 1986), the score is presented in age percentiles and the resulting ordinal data are more difficult to analyse than the numerical BSID DQ. However both instruments have been found to classify children into similar categories (Bayley, 1993).
The question therefore under study is whether the motor development of isiXhosa speaking children living in resource poor areas of Cape Town has remained the same or declined in the 20 years since Irwin-Carruthers concluded that children resident in these same areas of Cape Town demonstrated advanced motor skills compared to the North American norming sample. Secondary objectives of the study were to determine which factors were predictive of the motor quotient of the participants.

\section{METHODOLOGY}

The study utilised a descriptive, cross sectional design. The data were collected from 2003 to 2004 from children, living in the same resource poor areas of the Western Cape that had formed part of the original study by Irwin-Carruthers. As in her study, participants were recruited from children between the ages of birth and 36 months attending well baby clinics. This age bracket was chosen because children of these ages are brought in for routine vaccination and it is relatively easy to obtain a representative sample. Although it was necessary to try to exclude children infected with HIV, it was not ethically acceptable to test the children for HIV solely for the purposes of the study and consequently the sample may have contained children who were HIV positive. However, to minimise this possibility, all children who had had a history of typical HIV opportunistic infections, such as tuberculosis or meningitis, or who had recurrent hospital admissions (more than three and any one for longer than seven days), were excluded. Children who had been diagnosed with HIV were excluded. All the children came from isiXhosa speaking families and in all but two cases were accompanied by their biological mother.

\section{Instrumentation}

One of the investigators underwent a two week training and spent three months familiarising herself with the use of the BSID-II before commencing data gathering. The corrected age, i.e. age taking prematurity into account, was used to calculate the Psycho-motor development index (PDI). A small reliability test was done on 10 children and it was found that the two testers had a $90 \%$ rate of agreement on their scores. The isiXhosa version of the EQ-5D (Brooks and EuroQol Group, 1996) was chosen to monitor the health related quality of life of the mothers and caregivers as it has been found to be reliable and valid for a similar population to that under study (Jelsma et al., 2004a). The visual analogue scale of the EQ-5D was used to investigate the perceived health related quality of life of the mothers. The score ranges from worst imaginable health $=0$ to best imaginable health $=100$.

\section{Procedure}

Approval for the study was obtained from the Medical Research Ethics Committee of the University of Cape Town. Permission to approach participants was granted by the medical personnel in charge of the three different

Table 1: Number of children in each two month age band. $\mathrm{N}=86$.

\begin{tabular}{|l|ll|}
\hline Age in months & Frequency & $\%$ \\
\hline $\mathbf{0 - 1 . 9}$ & 2 & 2.3 \\
\hline $\mathbf{2 - 3 . 9}$ & 11 & 12.8 \\
\hline $\mathbf{4 - 5 . 9}$ & 13 & 15.1 \\
\hline $\mathbf{6 - 7 . 9}$ & 7 & 8.1 \\
\hline $\mathbf{8 - 9 . 9}$ & 10 & 11.6 \\
\hline $\mathbf{1 0 - 1 1 . 9}$ & 8 & 9.3 \\
\hline $\mathbf{1 2 - 1 3 . 9}$ & 9 & 10.5 \\
\hline $\mathbf{1 4 - 1 5 . 9}$ & 5 & 5.8 \\
\hline $\mathbf{1 6 - 1 7 . 9 9}$ & 2 & 2.3 \\
\hline $\mathbf{1 8 - 1 9 . 9}$ & 3 & 3.5 \\
\hline $\mathbf{2 0 - 2 1 . 9}$ & 4 & 4.7 \\
\hline $\mathbf{2 2 - 2 3 . 9}$ & 0 & 0.0 \\
\hline $\mathbf{2 4 - 2 5 . 9}$ & 4 & 4.7 \\
\hline $\mathbf{2 6 - 2 7 . 9}$ & 3 & 3.5 \\
\hline $\mathbf{2 8 - 2 9 . 9}$ & 1 & 1.2 \\
\hline $\mathbf{3 0 - 3 1 . 9}$ & 2 & 2.3 \\
\hline $\mathbf{3 2 - 3 3 . 9}$ & 2 & 100.0 \\
\hline $\mathbf{3 4 - 3 5 . 9}$ & 0 & \\
\hline Total & 86 & 3.2 \\
\hline
\end{tabular}


clinics from which children were recruited. The care-givers were approached whilst waiting to receive attention from the medical staff. Informed consent was obtained and the care-giver was asked demographic questions by an isiXhosa interpreter. The BSID-II and EQ-5D were then administered in a separate room by one of the researchers with the assistance of the isiXhosa translator.

\section{Statistical analysis}

Descriptive statistics were used to describe the socio-demographic characteristics of the sample. The ShapiroWilks test was used to test for normality of the PDI distribution. General linear modelling (GLM) was used to determine interaction effects between the dependent variable, PDI and the independent variables of mother's years of education, mothers health related quality of life as measured on a visual analogue scale (VAS), type of residence (brick or informal), mother's HIV status (positive or unknown) and income category. Similarly GLM was used to test interaction effects between the PDI and the age of the child, number of hospitalisations, gender, presence of two or more of ear, chest or gastro-intestinal infections.

\section{RESULTS}

There were 89 children who were tested with the Bayley Motor Scale. Two children were excluded on the grounds of having had tuberculosis and of having had three hospital admissions and one other was excluded because of meningitis. This left an effective sample of 86 of which $47(54 \%)$ were male. The mean age was 11.9 months $(\mathrm{SD}=8.7$, range 1.4 to 33.5). The numbers of children of each age is given in Table 1 and it can be seen that the children were spread across the two month age bands from 0-36 months, with only two bands not being represented. Three children were born before 36 weeks gestational age and their corrected age was used to calculate their DQ. Eighteen had one or more hospital admission. Fourteen had previously had chest infections, 21 had previously had diarrhoea and 19 had had ear infections. Seven children had had both chest infection and diarrhoea and they were then coded as having had infections and this variable was included in the GLM.

All the children except two were with their mothers. In these cases, the aunt had brought the child to the clinic, as the mother was working. Sixteen $(23 \%)$ of the mothers were HIV positive, with the sero-status of 69 unknown. The children of the mothers, who were confirmed positive, had had a Polychromatase reaction (PCR) test and their negative status was confirmed. Ten of these children had been exposed to perinatal prophylactic anti-retroviral therapy. The mean age of the mothers and caregivers was 28.0 years (SD 6.5, range: 18-55 years). The majority of respondents were single $37(43 \%)$ with 31 either married $(20 \%)$ or living with partner.
Two were either divorced or separated and data on the marital status of 16 were missing.

Fourteen mothers did not give information on their educational status. The majority had reached high school (67, $78 \%$ ) and only one had tertiary education. Ten were employed and 46 (54\%) received the government chid support grant, which was the primary source of income for $40(47 \%)$ mothers. In 21 cases the father contributed income. Thirty four mothers/caregivers (49\%) did not know or wish to report on their monthly income, 33 mothers (38\%) reported receiving less that $\mathrm{R} 350$ income per month 16 (19\%), between R350-600 and 3 reported income in the bracket R600-1000. As the number not reporting was large, this variable was

\section{Figure 1: Histogram of the psychomotor development quotient. N=85}

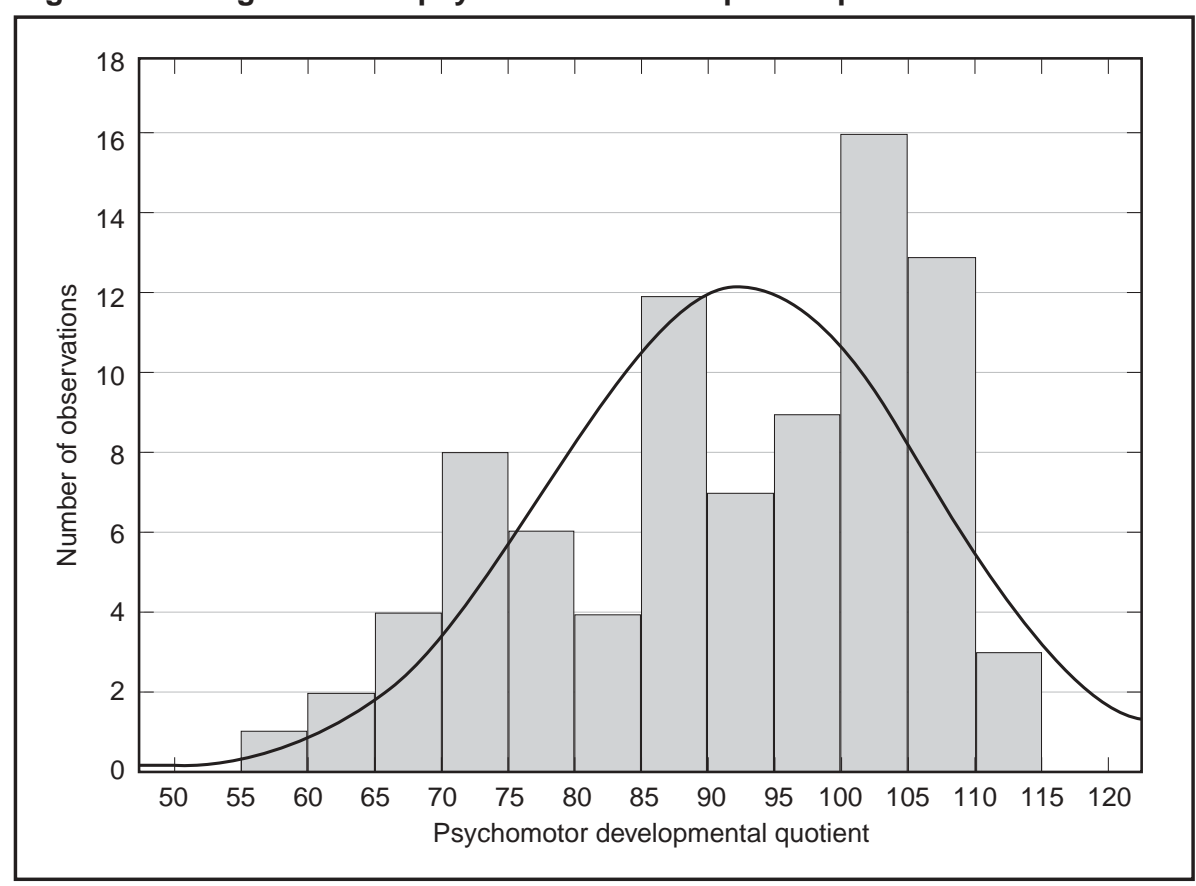

Table 2: Classification of performance based on the Psycho-motor score of the Bayley Scales of Infant Development ( $\mathrm{N}=85)$.

\begin{tabular}{|l|l|l|l|}
\hline & Count & Percent & $\begin{array}{l}\text { Norming Sample } \\
\text { (Bayley, 1993) } \\
\text { Percent }\end{array}$ \\
\hline Significantly delayed & 3 & 3.5 & 2.3 \\
\hline Mildly delayed & 21 & 24.7 & 12.5 \\
\hline Within normal limits & 61 & 71.7 & 68.7 \\
\hline Accelerated performance & 0 & 0 & 16.5 \\
\hline
\end{tabular}

Degrees of freedom: 3

Chi-square $=20.8$

$\mathrm{p}<0.001$. 
not entered into the GLM. Sixty-six mothers $(77 \%)$ lived in informal settlements rather than brick housing.

The mean psycho-motor development index (PDI) was 92.0 ( $\mathrm{SD}=15.0)$. There clearly was one outlier, who achieved a PDI of 40. There was no apparent reason for this low score, as the child was born at term, had had a birth weight of 2800, had no hospital admissions and had no history of chest infections or diarrhoea. The child's parents were married, employed and the family lived in a brick house. The decision was taken to exclude the data from this child as it would introduce a bias downwards. On exclusion, the mean was 92.3 and the $\mathrm{SD}=13.9$ (Median=94, Range 60-114). The histogram of the values is depicted in Figure 1. The data were not normally distributed ( $\mathrm{W}=.94, \mathrm{p}=.001)$.

The BSID allows for classification of expected performance based on the specific PDI score. In Table 2, it can be seen that 24 children (28\%) were either significantly or mildly delayed. This distribution was significantly different $(\mathrm{p}<.001)$ from the distribution of the norming sample.

The mean of the visual analogue score of the mothers was 71.2 $(\mathrm{SD}=13.1)$

The results of the GLM of maternal and socio-economic characteristics are in Table 3.

The adjusted $r^{2}$ value, which is the proportion of the variance that is attributable to the variables entered into the model, was low, $.078,(\mathrm{p}=.27)$ i.e. only about $8 \%$ of the variance was due to the factors entered. No coefficients of variables or interaction effects were significant and the model did not predict the PDI well.

Table 3: Results of the GLM to determine interaction effects of maternal characteristics with the PDI.

\begin{tabular}{|l|l|l|l|l|l|}
\hline & $\begin{array}{l}\text { Level of } \\
\text { Effect }\end{array}$ & $\begin{array}{l}\text { PDI } \\
\text { Parameters }\end{array}$ & $\begin{array}{l}\text { PDI } \\
\text { Std. Err }\end{array}$ & $\begin{array}{l}\text { PDI } \\
\text { t value }\end{array}$ & $\begin{array}{l}\text { PDI } \\
\text { p value }\end{array}$ \\
\hline Intercept & & 139.73 & 29.19 & 4.79 & 0.00 \\
\hline Mother's age years & & -0.46 & 0.37 & -1.26 & 0.22 \\
\hline Mother's education years & & -2.27 & 1.41 & -1.61 & 0.11 \\
\hline Mother's VAS & & -0.29 & 0.17 & -1.66 & 0.11 \\
\hline Caregiver HIV status & positive & -5.29 & 6.55 & -0.81 & 0.42 \\
\hline $\begin{array}{l}\text { Category of marital } \\
\text { relationship }\end{array}$ & single & 3.74 & 8.73 & 0.43 & 0.67 \\
\hline Mother employed & yes & -10.30 & 11.42 & -0.90 & 0.37 \\
\hline Child support grant & no & 12.53 & 13.00 & 0.96 & 0.34 \\
\hline Child support grant & yes & 5.81 & 8.47 & 0.69 & 0.50 \\
\hline Housing status & informal & -8.86 & 5.51 & -1.61 & 0.12 \\
\hline
\end{tabular}

Table 4: Results of the GLM to determine interaction effects of the infant's characteristics with the PDI.

\begin{tabular}{|l|l|l|l|l|l|}
\hline & $\begin{array}{l}\text { Level of } \\
\text { Effect }\end{array}$ & $\begin{array}{l}\text { PDI } \\
\text { Parameters }\end{array}$ & $\begin{array}{l}\text { PDI } \\
\text { Std. Err }\end{array}$ & $\begin{array}{l}\text { PDI } \\
\mathbf{t} \text { value }\end{array}$ & $\begin{array}{l}\text { PDI } \\
\mathbf{p} \text { value }\end{array}$ \\
\hline Intercept & & 93.38 & 3.90 & 23.92 & 0.00 \\
\hline Corrected age (months) & & -0.26 & 0.20 & -1.29 & 0.20 \\
\hline Gender & female & 0.30 & 2.13 & 0.14 & 0.89 \\
\hline Admitted to hospital & yes & 1.50 & 2.99 & 0.50 & 0.62 \\
\hline Two or more infections & no & 0.92 & 2.95 & 0.31 & 0.76 \\
\hline
\end{tabular}

Table 4 depicts the GLM of the interaction effects of the PDI and the variables related to the children. As for the maternal characteristics, no variable related to the child predicted the PDI. The adjusted $\mathrm{r}^{2}$ value was similarly low, $.062, \mathrm{p}=.12$. The model did not predict the PDI well and no interaction effects were significant.

\section{DISCUSSION}

The sample was not large and the results need to be treated with caution. The sample included children from most two month age categories and included a similar number of both males and females. Although it cannot be said with certainty that all children with HIV were excluded, the children who had a history of illness and were retained as part of the sample did not score below the rest of the sample. The mothers appear to fall into a similar income bracket as those in Irwin-Carruthers study (Irwin-Carruthers, 1986), $97 \%$ of which reported monthly income of less than R500 per month, although allowing for inflation, the actual purchasing power of the income could be lower. However, only $20 \%$ of the mothers lived with common law husbands compared to $38.8 \%$ in her sample. This may not have had an independent impact, though, as the maternal marital status did not influence PDI score.

The two studies appear to be comparable and it is worrying that not only did the South African sample under study not perform better than their counterparts, as in the 1986 study, their performance has decreased to the extent that their motor performance would now appear to be a mean $10 \%$ less than their peers. Admittedly the PDI data was not normally distributed but this decrease is remarkably similar to the results of the two studies on the samples of children from the same area, one of which used the BSID-II (Matyida and Jelsma, 2004) and the other which used the AIMS scale (Jelsma et al., 2004b). In addition, the comparison between the classification of performance of the sample and the norming sample tells a similar story. Over $25 \%$ of the South African sample demonstrated delayed performance, compared to $15 \%$ of the norming 
sample. No South African children demonstrated accelerated development compared to the $16.5 \%$ of Bayley's sample (Bayley, 1993).

It is difficult to know exactly what factors are responsible for the decrease in PDI, as none could be identified through this study. The decrease could be as a result of the poverty and the living conditions that might have deteriorated. The original study by IrwinCarruthers (Irwin-Carruthers, 1986) study took place against the backdrop of apartheid under which migration from rural to urban areas ("influx control") was strictly controlled and Black Africans were not allowed to move to cities unless they had employment. Consequently, the sample on which the Denver Scales were normed would have represented a group of children from a relatively stable economic background.

Since the advent of a democratic system of government, the so called "pass-laws" which required that Black Africans needed permits to prove employment and consequent right to residence in cities, has been repealed. This has resulted in a free movement of people from areas in which there is little unemployment into urban areas and has lead to a dramatic increase in population. The black population of the township areas around Cape Town has grown from approximately 700,000 in 1993 to an estimated 1,226,000 people in 2005 (City of Cape Town, 2005). In August, 2005 , it was estimated that 500,000 people were still living in informal settlements and that a further 16,000 people move to the informal settlements of Cape Town every year (Staff Reporter, 2005). Many of the new immigrants to the city do not have formal housing and live in informal settlements with limited access to water and sanitary facilities. In addition, many are still unemployed and rely on grants as their only source of income, as indicated by the large number of mothers whose sole source of income was child support grants. Richter and Grieve, have established that quality of the home environment does impact on the child's development (Richter and Grieve, 1991) and this is an aspect which needs to be examined in further studies.
Despite the clear commitment by the City of Cape Town to upgrade services and facilities to the informal settlement areas, (Cape Town City, 2005) and the freely available child support grant which must aid in the alleviation of poverty to a certain extent, the situation of many of the mothers appears dire. Abbot and Bartlett highlight the impact that deprivation, parental expectations and poverty have on infant motor development (Abbott and Bartlett, 1999) and the decrease in motor performance could be reflection of the poor socioeconomic status of the mothers.

The perceived health related quality of life of the mothers, as the measured by the visual analogue scale, was low (71.2, $\mathrm{SD}=13.1)$, compared to the VAS of $77.8(\mathrm{SD}=22.7)$ reported in a similar population (Jelsma et al., 2004a).

Another possibility for the decrease in performance could be the use of the BSID II. Studies on the use of the Second version have concluded that children need a higher raw score to get the same index score as children are now performing better than when the standardisation data for the original BSID were collected (Bayley, 1993). This would imply that the South African sample is not performing at a lower level than the 1986 sample, but that their performance has not increased at the same rate as their peers in North America.

At first glance it seemed surprising that no factors, housing, income, caregiver's educational level, seemed to impact on the PDI score. Other studies have consistently reported that these factors influence developmental outcome (Goyen and Lui, 2002). However, this finding is similar to that of Richter and Grieve, who found no significant association between cognitive levels of functioning and parental education or occupation in urban black South African children (Richter and Grieve, 1991). On examination it is clear that the sample was in fact homogenous. For example, the absolute difference between an income of maximum R300 and maximum R600 per month is not very large. Generally the mothers all seemed to be in a poor socio-economic situation and it is hypothesised that the combination of low income levels, poor living condi- tions, lack of a male father figure and unemployment combined lead to the apparent decrease in motor performance in this sample.

There are several implications to the fact that this group of South African children are performing at a lower level than their peers, and at a lower level than a sample tested 20 years previously, although the majority of the children are still performing within normal limits. The first, most obvious implication is that, if the BSID-II are to be used to monitor the development of any group of children suspected of having delayed development, the normed values should be treated with caution and possibly 90 should be taken as the mean score (rather than 100, with a SD of 15). If this is not taken into consideration, children with, for example HIV/AIDS may be reported as being more delayed than is in fact the case.

The second implication is that the performance is likely to be symptomatic of the dire socio-economic situations of the mothers. The $50 \%$ decrease in the number of mothers resident with common law husbands is another cause for concern. The introduction of child support grants has obviously been vital as in many cases this was the sole source of income. However, mothers resident in informal settlements seem to be particularly in need of emotional and financial support.

The long term implication of the decreased PDI is not clear. There is not strong evidence of the predictive validity of the BSID-II PDI although low scores on the BSID do appear to be more predictive of later intellectual functioning than scores in the middle or upper ranges. In this study over one quarter of the children fell into the severely or mildly delayed categories. As there is evidence of continuity between early low scores and later motor performance (Barnhart et al., 2003), it is possible that these children will be clumsy and perform badly in sport and other physical activities at school. None of these children were referred for intervention as there is no physiotherapy service within the public sector for children whose motor performance is minimally decreased. The long term effect on 
self-esteem and performance should be further researched.

This study adds further evidence to the debate regarding theories of motor development (Hadders-Algra, 2000) and the considerable influence that the environment plays in determining the rate of development and would challenge the neural maturational theory of development.

\section{CONCLUSION}

Based on this small sample, it appears that IsiXhosa speaking children in resource poor areas of Cape Town are scoring $10 \%$ lower in the BSIDII than their North American peers. This is particularly concerning as this same group was performing better than the norming sample in 1986. The reasons for the decrease in performance are not clear. The socio-economic situation of the mothers is poor and there are an increasing number of single mothers whose sole source of income is government child support grants. The BSID-II has been revised and it could be that the North American sample has made motor progress, whereas the South African sample has remained static.

It is likely that the cause of the decrease is multi-factorial as the mothers are clearly in need of emotional and financial support. As intervention programmes have been found to impact on motor control (Barnhart et al., 2003), it is recommended that programmes of stimulation of motor activity might be useful in reducing the long term impact of this delayed development.

\section{COMPETING INTERESTS}

The authors have no competing interests

\section{AUTHORS CONTRIBUTION}

Jennifer Jelsma and Gillian Ferguson conceptualised the study. Gillian Ferguson collected the data and Jennifer Jelsma analysed it and wrote the paper. Gillian Ferguson approved the final draft.

\section{ACKNOWLEDGEMENTS}

Medical Research Council of South Africa, University of Cape Town Research Committee. Dr. Annelies Rie for support and Ms Thembagazi for translation. University of the Witwaters- rand and Joanne Potterton for arranging training in the use of the BSID.

\section{REFERENCES}

Abbott A, Bartlett D. 1999. The relationship betwen the home environment and early motor development. Physical and Occupational Therapy in Pediatrics 19:43-57.

Barnhart RC, Davenport MJ, Epps SB, Nordquist VM. 2003. Developmental coordination disorder. Physical Therapy 83:722-731.

Bayley N. 1993. Bayley Scales of Infant Development, 2nd ed. Orlando, Boston, New York: The Pychological Corporation.

Brooks R, EuroQol Group. 1996. EuroQol: the current state of play. Health Policy 37:53-72.

Cape Town City. 2005. Annual Report 2003/2004. July 2005, 2005 http://www. capetown.gov.za/reports/2003-2004/ annual_report.pdf

City of Cape Town. 2005. Demographics. July 2005, 2005 http://www.capetown.gov.za/ home/demographics.asp

Coetzee D, Hildebrand K, Boulle A, Maartens G, Louis F, Labatala V, Reuter H, Ntwana N, Goemaere E. 2004. Outcomes at 24 months in a primary care antiretroviral treatment programme in South Africa. AIDS $18: 1-9$.

Cooper PJ, Landman M, Tomlinson M, Molteno C, Swartz L, Murray L. 2002. Impact of a mother-infant intervention in an indigent peri-urban South African context: pilot study. British Journal of Psychiatry 180:76-81.

Denckla MB. 2005. Why assess motor functions "early and often?" Mental Retardation and Developmental Disability Research Review 11:3.

Frankenburg WK, Dodds JB. 1967. The Denver developmental screening test. Journal of Pediatrics 71:181-191.

Goyen TA, Lui K. 2002. Longitudinal motor development of "apparently normal" high-risk infants at 18 months, 3 and 5 years. Early Hum Dev 70:103-115.

Hadders-Algra M. 2000. The neuronal group selection theory: a framework to explain variation in normal motor development. Dev Med Child Neurol 42:566-572.

Irwin- Carruther, S. 1986. A cross-cultural study of motor development in the Western Cape. MSc Physiotherapy thesis, University of Cape Town.
Jelsma J, Amosun D, Mkoka S, Nieuwveld J. 2004a. The reliability and validity of the Xhosa version of the EQ-5D. Disability and Rehabilitation 26:103-108.

Jelsma J, Peters L, van Bekbergen R, Feys H. 2004b. Development of children on HAART. (Using Alberta Infant Motor Scale). In: Human Sciences Research Council, editor. 2nd African Conference on Social Aspects of HIV/AIDS Research, SAHARA. Cape Town.

Matyida N, Jelsma J. 2004. The development of children with HIV receiving HAART. In: Occupational Therapy Association of South Africa Congress. Cape Town: Occupational Therapy Association of South Africa.

Piper M, Darrah J, Boyce N. 1994. Motor assessment of the developing infant. Philadelphia: Saunders.

Potterton J, Eales C. 2001. Prevalence of Developmental Delay in Infants who are HIV Positive. South African Journal of Physiotherapy 57:11-15.

Richter LM, Grieve KW. 1991. Home environment and cognitive development of black infants in impoverished South African families. Infant Mental Health Journal 12:88 - 102.

Staff Reporter. 2005. 500000 live in shacks and 16000 more arrive every year. In: Cape Argus. Cape Town. p 3.

UNAIDS. 2002. Fact Sheet 2002 - SubSaharan Africa. April, 2003 http://www.unaids. org/worldaidsday/2002/press/factsheets/FSAf rica_en.doc 